\title{
O DESASTRE SOCIOAMBIENTAL DA SAMARCO: RASTREANDO AS CONTROVÉRSIAS A PARTIR DE UMA OFICINA PEDAGÓGICA COM JORNAIS
}

\section{SAMARCO'S SOCIO-ENVIRONMENTAL DISASTER: TRACING CONTROVERSIES FROM A PEDAGOGICAL OFFICE WITH NEWSPAPERS}

\author{
Alexsandro Luiz dos Reis* \\ Fábio Augusto Rodrigues e Silva*
}

\begin{abstract}
RESUMO: O presente trabalho apresenta o rastreio das controvérsias que se emergiram a partir do desenvolvimento de uma oficina pedagógica de produção de textos jornalísticos, com uma turma em ano final do ensino médio da rede pública de ensino. Nesse caminho, utilizamos como suporte teórico-analítico os princípios da Teoria Ator-Rede (TAR) para analisarmos as circulações, fluxos e movimentações, a partir das translações entre os actantes, no caso deste trabalho, alunos, professor e jornais. Decorridas as análises observamos que a partir dos momentos de discussões, debates e produção escrita realizada, muitas foram as controvérsias que se emergiram. Ressaltamos ainda, que por meio da oficina pedagógica com jornais, os alunos puderam discutir as nuances do desastre, bem como discutir e refletir sobre as intencionalidades das matérias que continham o desastre como manchete. Dessa forma, a oficina se apresenta como um importante mecanismo para que os alunos possam trabalhar as implicações da pior tragédia socioambiental ocorrida no Brasil.
\end{abstract}

Palavras-chave: Controvérsias; Desastre; Oficina.

ABSTRACT: The present work presents the screening of the controversies that emerged from the development of a pedagogical workshop to produce journalistic texts, with a class in the final year of high school teaching. In this way, we use as theoretical-analytical support the principles of the Actor-Network Theory (TAR) to analyze circulations, flows and movements, from the translations among the actants, in the case of this work, students, teacher and newspapers. After the analyzes we observed that from the moments of discussions, debates and written production, many controversies emerged. We also emphasize that through the pedagogical workshop with newspapers, students were able to discuss the nuances of the disaster, as well as discuss and reflect on the intentionalities of the subjects that contained the disaster as a headline. In this way, the workshop presents itself as an important mechanism for students to work on the implications of the worst socio-environmental tragedy in Brazil.

Keywords: Controversies; Disaster; Workshop.

\footnotetext{
* Mestrado em Ensino de Ciências pela Universidade Federal de Ouro Preto (UFOP). Docente da educação básica da rede pública em Minas Gerais. Contato: alexreis923@gmail.com

* Doutorado em Educação pela Universidade Federal de Minas Gerais (UFMG). Docente da Universidade Federal de Ouro Preto (UFOP). Contato: fabogusto@gmail.com
} 


\section{INTRODUÇÃO}

5 de novembro de 2015 será um dia jamais esquecido pelos moradores do subdistrito de Bento Rodrigues, situado a $35 \mathrm{~km}$ da histórica cidade de Mariana-MG. Nessa data, por volta das 16 horas e 30 minutos, aproximadamente 34 milhões de metros cúbicos de rejeitos liquefeitos (SERRA, 2018), provenientes do rompimento da Barragem de Fundão, assolaram em questão de minutos a localidade, atingindo pouco tempo depois os subdistritos vizinhos como: Paracatu de Baixo, Gesteira, Camargos e a cidade de Barra Longa. Esse tsunami de lama deixou incalculáveis prejuízos para a fauna, ictiofauna, flora, além de ter provocado 19 mortes e 1 desaparecido. Aqui, não podemos deixar de mencionar as implicações deste rastro de lama para os rios Doce, Gualaxo do Norte e do Carmo. Estudos e análises técnicas apontam que diversos percursos hídricos encontram-se contaminados pela elevação de metais pesados e por partículas em suspensão (CEAT, 2016; GIAIA, 2016; IGAM, 2016), fatores que acarretam em desequilíbrio para os ecossistemas aquáticos de bacias já tão degradadas anteriormente.

O desastre da Samarco é tido como a maior tragédia socioambiental ocorrida no Brasil (CARMO et. al, 2016), sendo que até a presente data são inúmeras as implicações para a população e cidade atingidas, além das tribos indígenas e populações ribeirinhas. Nesse cenário, temos centenas de famílias que aguardam apreensivamente o pagamento de indenizações ou outras compensações por parte da empresa, advindas pelos danos causados pela lama de rejeitos, bem como o reassentamento e, por conseguinte a construção de uma nova "Bento Rodrigues". Temos ainda várias cidades dos estados de Minas Gerais e do Espírito Santo que convivem diariamente com problemas de abastecimento com água potável, retração na economia e desemprego. Tais impactos são decorrentes da inoperância da empresa que implica no não pagamento de royalties, além da suspensão de algumas atividades econômicas como a pesca que eram realizadas por comunidades ribeirinhas. Por fim, salientamos que esta tragédia também afetou as tribos indígenas. Para tanto, destacamos os índios Krenak, que estão com sua identidade cultural esfacelada, uma vez que práticas para sua subsistência, como a pesca, a 
realização de rituais e outras crenças, além de atividades corriqueiras como as de banho no Rio Doce não estão sendo mais realizadas.

É bem provável que os efeitos provenientes do rompimento da Barragem de Fundão, perdurem por um longo período, e que a extinção de espécies endêmicas da região, bem como espécies da ictiofauna, seja registrada em poucos anos. Nesse caminho, ainda não podemos deixar de mencionar os transtornos para os atingidos, que convivem diariamente com danos em sua saúde e psicológicos, pós-desastre. Tais transtornos agravam-se com o passar do tempo, uma vez que a empresa não assiste os atingidos com o devido cuidado que estes necessitariam como o pagamento de planos de saúdes para exames e consultas periódicas.

Ressaltamos ainda que o desastre da Samarco deve ser considerado como um alerta para toda a sociedade brasileira, uma vez que dados do Cadastro Nacional de Barragens de Mineração - CNBM, apontam que no Brasil há 839 barragens, sendo 449 no ramo da mineração e tendo Minas Gerais com 369 barragens (DNPM, 2016).

Nesse cenário asseveramos aqui que a regulamentação e fiscalização relativas à segurança de barragens ainda é um desafio no Brasil, apesar das muitas diretrizes com vistas à proteção e segurança de barragens. Para tanto destacamos o Plano Nacional de Segurança de Barragens instituído no ano de 2010, tal documento possui como objetivo auxiliar as empresas no que tange à segurança das barragens, além de conter diretrizes para a construção, operação e manutenção dessas barragens (BRASIL, 2010).

Todavia, o quadro observado no Brasil nos remete a falhas na fiscalização por ausência, insuficiência ou despreparo do poder público. Entendemos que as empresas do ramo da mineração, como a Vale, beneficiam-se por ser:

[...] a maior empresa mundial neste ramo, além de grande financiadora de partidos e políticos que, após eleitos, atuam parcial e irresponsavelmente como legisladores e gestores. Isso fortalece a crescente autorregulação das empresas e o enfraquecimento do Estado na regulação e fiscalização. $O$ caso do licenciamento ambiental da barragem rompida da Samarco é tragicamente exemplar e demonstra a enorme assimetria entre a velocidade dos investimentos e a incapacidade/cumplicidade do Estado (PORTO, 2016, p. 2). 
Portanto, para revertermos esse contexto é necessário que outras iniciativas sejam implementadas, em que instituições da sociedade civil, academia, movimentos sociais e atingidos, se mobilizem contra as práticas adotadas pelas empresas mineradoras e suas influências políticas no cenário nacional. Dessa forma, acreditamos que a regulação, fiscalização, além de medidas de precaução e prevenção nos desastres poderá ser mais eficaz.

É importante também ressaltarmos que ao contrário das barragens hidrelétricas, as barragens de rejeitos de minério podem ser modificadas:

[...] ao longo da vida útil dos reservatórios, que são construídos gradualmente pelas mineradoras com os próprios rejeitos à medida que os depósitos minerais são explorados. As empresas fazem alteamentos de rejeitos de forma gradual, para diluir os custos do processo de extração mineral (IBRAM, 2016, p. 39).

Tal cenário ficou comprovado, no caso do desastre da Samarco, que após laudos e perícias técnicas, apontaram para uma ineficiência na fiscalização, sucessivos alteamentos e uma capacidade acima do tolerado no volume de rejeitos, o que culminaram no rompimento da Barragem de Fundão (PCMG, 2016).

O pós-desastre nos remete a um quadro de muitos estudos, discussões e debates, tanto no âmbito da academia, como nas diferentes frentes judiciárias, entre economistas, ambientalistas, políticos, além de movimentos sociais como o Movimento por Atingidos por Barragens (MAB), que se mobilizam com vistas à reparação do meio ambiente, revitalização do Rio Doce e o cumprimento dos deveres da empresa para com os atingidos.

E nesse contexto, também acreditamos que o rompimento da Barragem de Fundão possa ser uma temática trabalhada nas salas de aula com alunos da educação básica. Para tal, neste trabalho apresentamos análises a partir de uma oficina pedagógica com jornais, em que rastreamos as controvérsias suscitadas após a leitura, discussão, debate e produção escrita, em que reportagens que abordavam o desastre da Samarco eram o nosso objeto de estudo.

Aliás, entendemos as controvérsias como "uma disputa, uma discussão ou um debate regular entre indivíduos ou grupos de indivíduos sobre um assunto de interesse comum" (VELHO e VELHO, 2002, p. 127). A partir desta 
concepção, acreditamos que os alunos por meio da oficina, após ler as reportagens sobre a tragédia, poderão discutir as nuances do desastre, debatendo sobre os interesses envolvidos, os conflitos, além das muitas disputas entre os diversos atores dessa tragédia socioambiental. Aqui, ainda ressaltamos que a partir destas controvérsias suscitadas nos possibilitam identificar os grupos e anti-grupos (LATOUR, 2012), que entram em disputa a partir de suas posições contrárias durante a oficina.

Portanto, é nesse caminho que rastreamos as principais controvérsias a partir de uma oficina pedagógica com jornais, sendo que para sua análise nos detemos nos estudos teórico-analíticos de Bruno Latour e a Teoria Ator-Rede (TAR) e que será pormenorizado na seção a seguir.

\section{A TEORIA ATOR-REDE COMO SUPORTE NO RASTREIO DAS CONTROVÉRSIAS}

A TAR emerge como uma nova teoria social na Europa na década de 1980, tendo como precursores estudiosos como Bruno Latour, Michel Callon, John Law, Madelaine Akrich, dentre outros. A teoria se assenta em algumas concepções importantes para o seu entendimento. A primeira delas trata dos humanos e das coisas, também denominado por Latour de não-humanos. De acordo com a TAR, tanto humanos e não-humanos são designados de actantes. Nesse caminho Latour assevera que "o mundo está repleto de actantes, que podem ser, simultaneamente, dotados de propriedades humanas, como a capacidade de fala, quanto de propriedades das coisas, como a solidez típica das rochas (LATOUR, 1994, p. 95)".

Logo, temos que a partir do ponto de vista da TAR, os humanos e nãohumanos estão em constantes associações, numa mútua relação entre actantes interativos e interagentes (OLIVEIRA e PORTO, 2016). Ressaltamos, que Latour foi um dos pioneiros a propagar que os não-humanos mobilizam, interferem e afetam os humanos, numa prática aqui de denominamos de sociomaterial (SILVA et al., 2016). Essa simetria generalizada é entendida como a não distinção entre os elementos humanos e não-humanos no tratamento de uma rede híbrida. Nesse caminho, não há um ator principal e 
todos os actantes são tomados como coadjuvantes, com o mesmo valor ontológico (LATOUR, 1994).

Deste modo, a partir da oficina com os jornais impressos distribuídos na região do desastre e tendo como pressuposto de se deter a uma prática sociomaterial, temos que os atores não-humanos, no caso deste trabalho os jornais impressos, juntamente com os alunos, poderão agir mutuamente, em uma completa "simbiose", tendo ao final um processo híbrido, heterogêneo de natureza e cultura. Aqui, ressaltamos que os jornais são uma nítida manifestação da ação humana, cercado por disputas, interesses e conflitos, permitindo a sociedade diariamente discutir e debater temas controversos ou não.

Nessa perspectiva ainda destacamos que:

[...] o jornal como recurso didático torna-se um importante instrumento para se trabalhar de forma pedagógica, uma vez que é um meio que dispõe de assuntos que permitem uma reflexão sobre as diferentes situações sociais e culturais proporcionando ao educando inúmeras formas de compreender o mundo. $O$ jornal apresenta a dinâmica social, expõe a vida acontecendo, e, como tal, aproxima o educando dos assuntos do momento. As fotografias, charges, quadrinhos, propagandas dentre outros gêneros trabalhados neste recurso proporcionam o enriquecimento da interpretação da realidade política e social e, principalmente do trabalho com a leitura e escrita na escola (SOARES, 2015, p. 2).

Somados a isto, entendemos que os jornais impressos funcionam como "porta-vozes" da sociedade. Nessa linha temos, por exemplo, que os atingidos pela lama da Samarco, publicam seus pontos de vistas no que tange 0 desastre por meio de um jornal: o A Sirene: para não se esquecer ${ }^{1}$.

Outras concepções advindas da TAR também são muitos importantes para a compreensão do social. Para tal, destacamos as premissas que definem as translações, as noções de redes e mediação. Iniciamos pelo conceito de translação que é fundamental para o entendimento da TAR, uma vez que ela se refere a:

Todos os deslocamentos por entre outros atores cuja mediação é indispensável à ocorrência de qualquer ação [...] as cadeias de

\footnotetext{
${ }^{1} \mathrm{O}$ jornal $A$ Sirene: para não esquecer é distribuído de maneira impressa e também possui sua versão digital no endereço eletrônico jornalasirene.com.br. Tal jornal é produzido pelos atingidos em comunhão com diversas entidades da sociedade civil. Nesse caminho, o jornal A Sirene apresenta para os leitores os anseios e angústias, como também as reinvindicações dos atingidos face a morosidade da justiça no julgamento de indenizações e reparação do meio ambiente, além da revitalização do Rio Doce.
} 
translação referem-se ao trabalho graças ao qual os atores modificam, deslocam e transladam seus vários e contraditórios interesses (LATOUR, 2001, p. 356).

Ainda nesse caminho, as translações podem ser compreendidas como "[...] um processo de minimização das controvérsias advindas de diferentes interesses. Para que translações ocorram, é preciso lidar com controvérsias, fruto dos diversos interesses dos actantes envolvidos" (CERRETO e DOMENICO, 2016, p. 90). E para tanto, destacamos que lidar com controvérsias é possibilitar abrir "caixas-pretas"2, como no desastre da Samarco, que se apresenta como um evento complexo e com muitos elementos, interesses e disputas em cena.

Outro elemento fundamental na TAR são as redes, que são compostas "por actantes sem uma hierarquia definida. A ausência de uma única entidade pode fazer toda a rede colapsar. Além disso, tais redes são "tênues, frágeis e esparsas" (LATOUR, 1993, p. 222).

Tomando esta premissa como referência, temos no caso da oficina com jornais uma rede de actantes, que reúne o professor também chamado neste trabalho de "construtor", os alunos, os jornais, canetas, lápis, lapiseiras, borrachas, etc. Todas as controvérsias foram suscitadas a partir destas associações e, por conseguinte suas discussões, debates e por último a produção escrita em que os alunos trabalharam o gênero notícia.

Por fim, apresentamos outro conceito relevante na TAR, trata-se da mediação. Seguindo essa perspectiva temos que:

[...] a mediação também é uma noção fundamental para a TAR, e o que produz as mudanças na constituição das redes por meio das traduções. A mediação é o que coloca os actantes em articulação, numa mesma hierarquia, sem obstáculos que separem uns dos outros. Os mediadores, diferentemente dos intermediários, não transportam sem modificação, e de seus efeitos não se podem deduzir causas (OLIVEIRA e PORTO, 2016, p. 68).

Ou seja, de acordo com a TAR, a mediação pode afetar os efeitos advindos das redes. A partir desse ponto de vista "os mediadores transformam, traduzem, distorcem e modificam o significado ou os elementos que supostamente veiculam" (LATOUR, 2012, p. 65).

\footnotetext{
2 De acordo com Latour (1999), uma "caixa-preta" são aparatos em que os actantes estão consolidados, tendo suas ações inquestionáveis em seu interior.
} 
Em vista disso, ainda enfatizamos que para rastrearmos as controvérsias e, por conseguinte fazer suas análises nos valemos da Cartografia das Controvérsias (CdC). Para tanto assim como Venturini (2010a, p.4), defendemos a premissa que "[...] as controvérsias, ao envolver todo tipo de ator, são conflitos, geram debates, mostram-se resistentes à redução da complexidade e são capazes de descrever o social em sua forma mais dinâmica". Ou seja, por meio da CdC, poderemos "[...] olhar para o social enquanto ele se faz, em um estado magmático (ora fluido, ora solidificado) [...]" (CERRETO e DOMENICO, 2016, p. 91).

Portanto, após tecermos estas considerações sobre alguns dos elementos da TAR, na próxima seção depreendemos, rastreamos e analisamos as controvérsias surgidas a partir da abertura da "caixa-preta" do desastre da Samarco baseada na oficina pedagógica com os jornais. Acreditamos que dessa forma, poderemos analisar o fluxo das associações, além de apontar e compreender o papel de cada actante por meio de seus "rastros" deixados nas redes.

\section{DESENVOLVENDO A OFICINA PEDAGÓGICA COM JORNAIS}

A oficina pedagógica com as reportagens de jornais que traziam como manchete o desastre da Samarco ocorreu em uma turma do $3^{\circ}$ ano do ensino médio, turno da manhã, durante a disciplina de Biologia. A turma era compreendida por trinta e três estudantes, em faixa etária de 16 a 19 anos, alfabetizados, de acordo com a série e faixa etária, sendo ainda considerada uma turma "tranquila de se trabalhar". Cabe aqui ressaltar que a maioria dos alunos desta turma possui familiares ou conhecidos ligados a alguma empresa do ramo da mineração que atua na cidade. Por fim, destacamos que a escola a qual a oficina teve seu desenvolvimento fica localizada na área urbana no interior de Minas Gerais, situada no Quadrilátero Ferrífero, tendo como base de sua economia a mineração e a siderurgia.

A oficina com jornais impressos é um dos resultados de um mestrado profissional, em que foi desenvolvido um produto educacional, no caso um 
caderno de oficinas, pelo qual professores da Educação Básica poderão desenvolver uma oficina de produção de textos jornalísticos com seus alunos.

Nessa linha, acreditamos que as oficinas pedagógicas são estratégias para um ensino e aprendizagem mais significativo, uma vez que:

As oficinas pedagógicas são situações de ensino e aprendizagem por natureza abertas e dinâmicas, o que se revela essencial no caso da escola pública - instituição que acolhe indivíduos oriundos dos meios populares, cuja cultura precisa ser valorizada para que se entabulem as necessárias articulações entre os saberes populares e os saberes científicos ensinados na escola (MOITA e ANDRADE, 2006, p. 11).

Ainda nesse caminho, entendemos que a oficina:

[...] se caracteriza como uma estratégia do fazer pedagógico onde o espaço de construção e reconstrução do conhecimento são as principais ênfases. É lugar de pensar, descobrir, reinventar, criar e recriar, favorecido pela forma horizontal na qual a relação humana se dá. Pode-se lançar mão de músicas, textos, observações diretas, vídeos, pesquisas de campo, experiências práticas, enfim vivenciar ideias, sentimentos, experiências, num movimento de reconstrução individual e coletiva (ANASTASIOU e ALVES, 2004, p. 95).

Dentro desta perspectiva, a oficina teve quatro momentos em seus dois dias de desenvolvimento, de acordo com o (Quadro 1) abaixo:

Quadro 1: panorama da oficina com jornais

\begin{tabular}{|c|c|l|}
\hline \multicolumn{2}{|c|}{ Oficina pedagógica com jornais } \\
\hline $\mathbf{1}^{\circ}$ dia & Momentos & \multicolumn{1}{c|}{ Atividades } \\
\hline $\mathbf{1}^{\circ}$ & $\begin{array}{l}\text { Inserção dos alunos em grupos e mobilização do professor com } \\
\text { vistas às informações preliminares sobre o desastre. }\end{array}$ \\
$\mathbf{3}^{\mathbf{0}}$ & $\begin{array}{l}\text { Distribuição das reportagens sobre o desastre nos grupos formados. } \\
\text { Levantamento das controvérsias emergidas a partir da leitura, } \\
\text { discussão e debate sobre as reportagens. }\end{array}$ \\
\hline $\mathbf{2}^{\circ}$ dia & $\mathbf{4}^{\mathbf{0}}$ & $\begin{array}{l}\text { Produção individual escrita dos alunos, em que o gênero notícia foi } \\
\text { trabalhado. }\end{array}$ \\
\hline
\end{tabular}

Fonte: elaborado pelos autores. 
A partir deste panorama apresentado escolhemos para apresentar a seguir, quatro episódios em que vieram à tona os momentos de translações entre os actantes e, por conseguinte, as controvérsias emergidas após as discussões e os debates.

No primeiro episódio, apresentamos as controvérsias emergidas a partir das discussões entre os grupos, em que como as mídias abordaram o desastre foi debatida. No segundo, destacamos os pontos de vistas distintos entre os actantes a partir das controvérsias que se suscitaram quando das intencionalidades dos jornais em divulgar imagens do desastre. No terceiro, mapeamos as controvérsias a partir dos debates sobre quais as "vozes" presentes nas matérias dos jornais. Por sua vez, o quarto e último episódio nos apresenta uma produção escrita, em que elencamos algumas considerações relevantes pautadas na perspectiva da TAR.

\section{ANÁLISE DAS CONTROVÉRSIAS RASTREADAS}

$1^{\circ}$ Momento: Inserção dos alunos em grupos e mobiliz ação do professor com vistas às informações preliminares sobre o desastre

Os trabalhos iniciais da oficina foram cercados de muitas expectativas por parte dos alunos, o que fizeram falar ao mesmo tempo em voz alta e de maneira desordenada. Dessa forma, o professor não conseguia dar andamento as atividades do dia. Passado alguns minutos, e com a classe já estabilizada o professor fez uma breve apresentação da oficina, além de expor a sequência de atividades que seriam desenvolvidas a partir daquele momento. Feitas as considerações iniciais, o professor mobilizou os alunos a se integrarem em oito grupos (1 a 8) com no máximo quatro componentes cada.

Em seguida, o professor instigou os alunos a relatar o que e como foi o desastre da Samarco de acordo com que as mídias informaram. Nesse momento, diversas posições contrárias foram observadas durante as discussões, e algumas "disputas" entraram em cena, entre os grupos e antigrupos formados por meio de seus "porta-vozes" (LATOUR, 2012).

Em face a esse cenário, apresentamos como os alunos expuseram sobre a abordagem do tema na grande mídia, conforme o quadro 2 a seguir. 
Ressaltamos que os nomes presentes nos trechos de fala são meramente fictícios, não revelando desta forma a identidade dos alunos integrantes da oficina.

\section{Quadro 2: a abordagem do desastre nas grandes mídias}

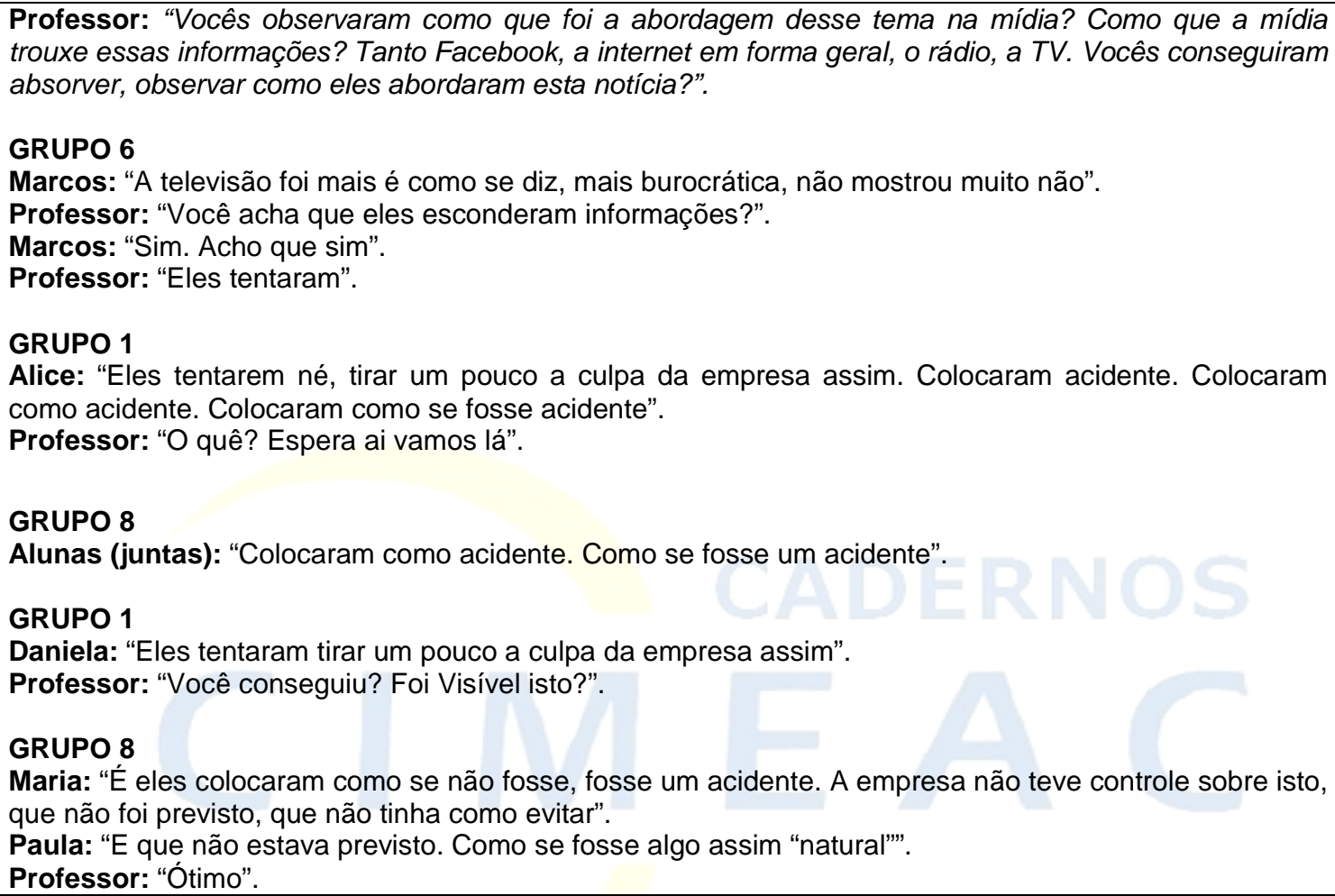
trouxe essas informações? Tanto Facebook, a internet em forma geral, o rádio, a TV. Vocês conseguiram absorver, observar como eles abordaram esta notícia?".

GRUPO 6

Marcos: "A televisão foi mais é como se diz, mais burocrática, não mostrou muito não".

Professor: "Você acha que eles esconderam informações?".

Marcos: "Sim. Acho que sim".

Professor: "Eles tentaram".

GRUPO 1

Alice: "Eles tentarem né, tirar um pouco a culpa da empresa assim. Colocaram acidente. Colocaram como acidente. Colocaram como se fosse acidente".

Professor: "O quê? Espera ai vamos lá".

GRUPO 8

Alunas (juntas): "Colocaram como acidente. Como se fosse um acidente".

GRUPO 1

Daniela: "Eles tentaram tirar um pouco a culpa da empresa assim".

Professor: "Você conseguiu? Foi Visível isto?".

GRUPO 8

Maria: "É eles colocaram como se não fosse, fosse um acidente. A empresa não teve controle sobre isto, que não foi previsto, que não tinha como evitar".

Paula: "E que não estava previsto. Como se fosse algo assim "natural"”.

Professor: "Ótimo".

Fonte: elaborado pelos autores.

Com base na narrativa apresentada, temos que os alunos são convidados a participar de uma rede, aos quais com o passar das discussões e debates, farão movimentos de translações entre eles, jornais e professor. Ainda de acordo com as narrativas apresentadas no quadro 2, destacamos a imprecisão dos dados no que tange a compreensão do que foi o rompimento da Barragem de Fundão. Nessa linha, destacamos que apesar da pergunta do professor citar outras mídias, como a rede social "Facebook", a internet e o rádio, os alunos se posicionaram de acordo com as informações veiculadas exclusivamente pela TV.

Premissa tal qual que fica bem evidente a partir da fala da Alice, que assevera que o desastre foi posto nos noticiários como "acidente". Além de Paula, que assevera também que colocaram nos jornais como "algo natural". 
Sabemos que após laudos e perícias sobre o desastre, o rompimento da Barragem de Fundão foi caracterizado como um crime, em que diversas multas, indenizações e reassentamento dos atingidos, bem como a reparação do meio ambiente, devem ser executadas pela empresa responsável pela tragédia.

Logo, a partir dessa condição apresentada, acreditamos que por meio da oficina com jornais, podemos auxiliar os alunos a construir outros "caminhos", fabricar outros "fatos", em que o desastre não será tido como um "acidente". Ademais, a partir da oficina temos alunos que podem seguir o caminho para a construção dos "fatos" do evento da Samarco a partir das matérias dos jornais, e os outros que se oporão a estas reportagens. Entendemos ainda que por meio do trabalho com as controvérsias, os alunos tem a possibilidade de desenvolver um espírito crítico e reflexivo no que tange o entendimento das intencionalidades presentes nas reportagens dos jornais, além de poder desenvolver princípios relevantes da cidadania, como o respeito, a ética, a justiça e o espírito de solidariedade.

A seguir apresentamos mais um processo de translação entre os actantes, em que é possível visualizar as negociações entre as entidades a partir de uma controvérsia suscitada após a distribuição de um novo actante na oficina, no caso, as reportagens dos jornais.

\section{$2^{\circ}$ Momento: Distribuição das reportagens sobre 0 de sastre nos grupos formados}

Realizadas as mobilizações iniciais pelo professor a despeito do desastre, um novo actante foi introduzido na rede de elementos da oficina. Tratava-se das reportagens dos jornais, que traziam em seus textos algumas das implicações do desastre em distintos âmbitos como economia, saúde, meio ambiente, justiça e o social.

Ressaltamos que o professor optou por escolher reportagens de jornais que circulavam periodicamente nas cidades da região dos Inconfidentes, como Ouro Preto, Mariana e Itabirito. Tal escolha foi devido ao fácil acesso da população a estes jornais, que também são distribuídos gratuitamente nestas cidades. 
Dentro desse contexto, a seguir pormenorizamos estas oito reportagens conforme o quadro 3, em que destacamos o jornal escolhido, as manchetes destes jornais, a área de implicação que o texto abordava, bem como o grupo que contemplou a reportagem para as discussões e debates.

Quadro 3: as reportagens distribuídas aos grupos

\begin{tabular}{|c|c|c|c|}
\hline Grupo & Jornal & Manchete & $\begin{array}{l}\text { Aspecto abordado na } \\
\text { reportagem }\end{array}$ \\
\hline 1 & Jornal Tribuna Livre & $\begin{array}{c}\text { "Samarco entrega para comunidade de Barra Longa a } \\
\text { Praça Manoel Lino Mol" }\end{array}$ & $\begin{array}{l}\text { Obras entregue pela Samarco à } \\
\text { população da cidade de Barra } \\
\text { Longa. }\end{array}$ \\
\hline 2 & $\begin{array}{l}\text { Jornal A Sirene: para } \\
\text { não se esquecer }\end{array}$ & "Declaração de amor a Paracatu" & $\begin{array}{l}\text { Manifestação dos moradores após } \\
\text { um ano do desastre no subdistrito } \\
\text { de Paracatu. }\end{array}$ \\
\hline 3 & Jornal O Liberal & $\begin{array}{l}\text { "Justiça de Mariana volta a julgar ação para indenizar } \\
\text { atingidos por desastre em Bento Rodrigues" }\end{array}$ & $\begin{array}{l}\text { Ação judicial contra a empresa } \\
\text { Samarco. }\end{array}$ \\
\hline 4 & $\begin{array}{l}\text { Jornal O mundo dos } \\
\text { Inconfidentes }\end{array}$ & $\begin{array}{c}\text { "Instalado o comitê que vai acompanhar as ações de } \\
\text { recuperação do Rio Doce" }\end{array}$ & $\begin{array}{l}\text { Ações de recuperação do Rio } \\
\text { Doce. }\end{array}$ \\
\hline 5 & Jornal O Liberal & "Moradores e autoridades se unem pró-Samarco" & $\begin{array}{l}\text { Moradores da cidade de Mariana } \\
\text { se manifestam para o retorno das } \\
\text { atividades da empresa na cidade. }\end{array}$ \\
\hline 6 & Jornal O Liberal & "Pela volta da geração de empregos" & $\begin{array}{l}\text { O prefeito de Mariana se reúne } \\
\text { com o presidente da República, } \\
\text { com vistas ao retorno da Samarco. }\end{array}$ \\
\hline 7 & $\begin{array}{l}\text { Jornal A Sirene: para } \\
\text { não se esquecer }\end{array}$ & "O laudo de Sofya" & $\begin{array}{l}\text { Apresenta os danos aos } \\
\text { moradores pela poeira de rejeitos } \\
\text { de minério na cidade de Barra } \\
\text { Longa. }\end{array}$ \\
\hline 8 & Jornal O Liberal & $\begin{array}{l}\text { "Possibilidade de reconstrução do Bento traz } \\
\text { esperanças a antigos moradores" }\end{array}$ & $\begin{array}{l}\text { Mostra os possíveis locais para a } \\
\text { reconstrução de Bento Rodrigues. }\end{array}$ \\
\hline
\end{tabular}

Fonte: elaborado pelos autores.

Salientamos que cada uma destas oito reportagens foi distribuída aleatoriamente aos grupos formados. Tais grupos tiveram um tempo prédeterminado pelo professor para uma leitura silenciosa, sendo que após a leitura, algumas indagações seriam feitas pelo professor como no episódio apresentado a seguir (QUADRO 4). Nele, o professor mobiliza os alunos a respeito das intencionalidades e do público, que as imagens do desastre visavam atingir quando publicadas nos jornais.

\section{Quadro 4: os pontos de vistas distintos entre os actantes a partir das controvérsias}

Professor: "Quais as intenções ou as motivações dos jornais ao divulgar imagens do desastre da Samarco? Que tipo de público que vocês acham eles pretender atingir?". 
GRUPO 1

Alice: "Os atingidos. Pra os atingidos e os outros das de outras cidades pra ter o acompanhamento da notícia. E tal. Aos atingidos mesmo".

\section{GRUPO 8}

Maria: "Ah...Eu acho que eles querem mostrar que a empresa não é tipo uma "vilã", que foi um acidente e tal, que ela tem que voltar a atividades. Eu acho pra".

Paula: "Poder gerar emprego pra eles novamente".

Maria: "Eu achei uma reportagem tendenciosa pra beneficiar a empresa mesmo então. Pra mostrar pro pessoal que ela não foi tão "ruim" assim".

Professor : "Ótimo". Mais alguém?".

Fonte: elaborado pelos autores.

A partir desta narrativa, temos outras controvérsias suscitadas a partir da discussão sobre quais as intencionalidades das imagens sobre o desastre, além de qual o público que elas visam atingir. Nesse sentido, destacamos a exposição dos pontos de vistas distintos entre os actantes. Por um lado, Alice, ressalta que as imagens são para os atingidos, por outro, Maria destaca que as imagens são para mudar a "imagem" da empresa na sociedade após o desastre.

Nesse caminho ficam evidenciados os actantes da rede a partir das controvérsias apresentadas. É ainda nesse momento, que fica perceptível as discordâncias entre os actantes, e a "disputa" de quais as intencionalidades na divulgação de imagens do desastre.

Dessa forma notamos, que a partir desta controvérsia, os "porta-vozes" (LATOUR, 2012), de cada grupo se associam, sendo que as redes formadas não se restringem somente aos grupos e anti-grupos formados, envolvendo desta forma outros elementos e conceitos que se interagem no mesmo plano ontológico.

Ainda nessas condições, destacamos que esta rede tecida entre alunos, professor e jornais, não se fecha, e pode a qualquer momento no tempo e no espaço, ter outros elementos agregados em sua estrutura, possibilitando que os fluxos, as circulações e alianças se estendam para todos os lados (LATOUR, 2012). Tal cenário é mapeado a seguir conforme o Diagrama 1: 


\section{Diagrama 1: Mapeamento dos actantes na oficina com os jornais}

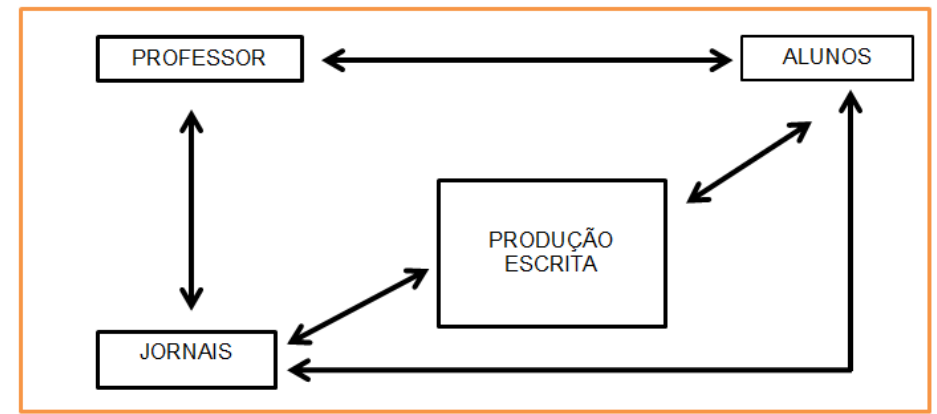

Legenda:

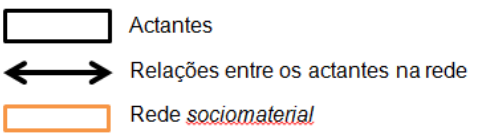

Fonte: elaborado pelos autores.

Com base no diagrama apresentado, temos que o professor convidou os alunos a agir mutuamente com as reportagens dos jornais (seta dupla do professor para os alunos). Para tanto, os alunos ao acolherem esse convite passaram a se transladar com os jornais (seta dupla alunos para os jornais). Nesse caminho, ainda temos que o professor também interagiu com as reportagens, uma vez que as escolheu previamente para a realização da oficina (seta dupla professor para os jornais). Por fim, os alunos relataram por meio de uma produção escrita, com base nos jornais (seta dupla jornais produção escrita), o que foi o desastre da Samarco em suas concepções (seta dupla alunos para produção escrita).

A seguir, destacamos mais um episódio em que emergem outras controvérsias, nas quais os alunos discutem sobre as "vozes" presentes nas reportagens dos jornais que são veiculadas para os leitores.

$3^{\circ}$ Momento: Levantamento das controvérsias emergidas a partir da leitura, discussão e debate sobre as reportagens

Neste terceiro episódio apresentado, evidenciamos as controvérsias que vieram à tona, quando os alunos discutiram as "vozes" presentes nas matérias dos jornais. Assim, o embate entre os grupos e anti-grupos formados se pautavam se os jornais traziam as "vozes" dos atingidos ou da empresa, conforme quadro 5, a seguir: 


\section{Quadro 5: as controvérsias suscitadas a partir das "vozes" presentes nos jornais} Professor: “Questão de número três. No texto vocês conseguiram observar mais fala dos atingidos ou
mais fala da empresa?".

\section{GRUPO 8}

Maria: "Aqui só tem fala do prefeito, presidente. Da empresa só. Dos atingidos não".

Professor: "Aqui?".

\section{GRUPO 5}

Ana: "No caso aqui da empresa. Só fala desse promotor aqui...na coletiva de imprensa...Só ele que fala. Ele que estava representando todo mundo".

Júlia: "Só ele que fala".

Professor: "Entendi. Ok. O de vocês?".

GRUPO 1

Alice: "O nosso tá falando dos recursos que a empresa vai fornecer para recuperar o rio. Da empresa".

\section{GRUPO 3}

Gabriela: "Aqui no nosso só fala de político, só tem fala de político falando de verba e que eles querem que a empresa volte por causa do desemprego".

Professor: "Ok. Aqui?".

GRUPO 2

Aida: "O nosso fala mais dos moradores, eles, dos atingidos".

Professor: "Dos atingidos? Ok".

GRUPO 4

Teresa: "É aqui mais, é , retrata mais os moradores. Tanto que tem uma parte aqui que fala do "Miguef", moradores atingidos na reportagem aqui".

\section{GRUPO 6}

Laura: "O nosso também se refere aos atingidos, principalmente a parte que fala do laudo de Sophya, tá se referindo, uma pessoa, uma garota, uma criança que sofria."

Professor: "Ótimo".

GRUPO 7

Rita: "Aqui quem fala só o presidente, diretor da Samarco, Roberto Carvalho. Ele cita que a população tá participando, mas não mostra a fala dela".

Fonte: elaborado pelos autores.

Aqui é importante observamos o seguinte. O professor tinha o objetivo que os alunos discutissem sobre as "vozes" presentes nas matérias dos jornais. Nesse caminho, conforme observamos nas narrativas acima, as controvérsias depreendidas são marcadas por uma distribuição heterogênea de "vozes". Para uns as "vozes" remetidas ao público dizem a respeito à empresa. Para outros são os atingidos que possuem uma "voz" mais ativa e estas são passadas para a sociedade. Acreditamos que esse cenário remetido aos jornais, se deve ao fato das reportagens se tendenciarem para um "lado" dos fatos, não veiculando para seus leitores a notícia com a devida imparcialidade que teve o acontecimento ou situação (SILVA e BALTAZAR, 2013). 
Ressaltamos ainda que as reportagens dos jornais se perfizeram em um actante que permitiram os alunos a identificação de quem fala em cada uma das reportagens dos jornais. Tal contexto trouxe para sala de aula, aspectos do mundo exterior, em que por meio das "vozes" dos jornais, atingidos e representantes da empresa expressam seus pontos de vistas no que tange às necessidades dos atingidos e possíveis caminhos para a recuperação do meio ambiente.

Finalmente, destacamos que por meio de uma questão sociocientífica, em que elementos da Ciência/Tecnologia/Sociedade/Meio Ambiente (CTSA) se relacionavam, os actantes, no caso, alunos e professor, puderam discutir de maneira reflexiva e crítica o papel dos "atores" envolvidos no desastre.

Dessa forma, acreditamos que os alunos aguçaram seu aprendizado por meio de uma leitura crítica das informações que apresentavam os jornais, além de desenvolver opiniões mais consistentes e embasadas, quando confrontadas controvérsias sociocientíficas ou socioambientais.

Como último episódio analisado neste trabalho, apresentamos a seguir uma produção escrita, que foi realizada no segundo dia da oficina, em que também apontamos algumas considerações importantes a partir da perspectiva da TAR.

\section{$4^{\circ}$ Momento: Produção individual escrita dos alunos, em que o gênero notícia foi trabalhado}

O segundo e último dia de oficina com jornais começou com o restabelecimento dos grupos do dia anterior. Em seguida, o professor distribuiu as reportagens pertencentes a cada grupo, além de folhas de papel ofício a cada aluno. Ele mobilizou os alunos a escrever um texto livre, trabalhando o gênero notícia, em que deveriam relatar o que foi o desastre da Samarco em suas concepções. O convite do professor teve uma boa acolhida por parte dos alunos. Os estudantes teriam que utilizar como embasamento para as suas produções, os momentos desenvolvidos no dia anterior, as matérias dos jornais distribuídas, além dos conhecimentos prévios a respeito do desastre, conforme produção escrita (Quadro 6) abaixo: 


\title{
Quadro 6: uma produção escrita sobre o desastre da Samarco
}

\begin{abstract}
GRUPO 5
Fátima: "Inicialmente eu pensava que foi um desastre natural, mas depois de toda repercussão vi que realmente era um crime precisamente. Foi um terrível acontecimento no dia 5 de novembro, numa quinta onde tudo aconteceu. O maior desastre de Mariana foi onde tudo ocorreu, destruindo sonhos e a vida dos atingidos. Os locais mais atingidos foram os distritos de Mariana, como Bento Rodrigues, Paracatu de Baixo, Paracatu de Cima, Barra Longa entre outros. A barragem que se rompeu chama-se Barragem de Fundão que pertence a Samarco mineração mais vale lembrar que a Vale e a PHP mineração também jogavam seus rejeitos nela. Contudo este rompimento originou várias consequências como a perda total de bens dos atingidos, desalojamento lembrando que a prefeitura de Mariana e a Samarco deu assistência de moradia, não como eles queriam mas foi feito. Atualmente quase não se fala desse acontecimento drástico, mas pelas próprias informações que tenho, os atingidos estão sendo aos poucos ressarcidos dos prejuízos e soma-se a isto o planejamento de uma nova cidade de Bento Rodrigues, para reunir novamente a comunidade. O importante é que a Samarco está arcando com todas as responsabilidades e o que é mais necessário para os atingidos que também teve prejuízos e abalos psicológicos. Torna-se assim esquematizar todas as necessidades e tentar desenvolver o máximo de ajuda a estes moradores. Retomando a tragédia em si têm-se como 19 mortos no período do acontecimento os bombeiros e toda cunha trabalhista investigadora, tiveram muito trabalho para achar os mortos em todo lamaçal que estavam soterrados. No dia do rompimento não houve nenhum alarme sonoro para alertar o que estava acontecendo, foram os próprios moradores responsáveis por avisar este ocorrido que foi dito".
\end{abstract}

Fonte: elaborado pelos autores.

A partir da análise da transcrição acima, acreditamos que a oficina com jornais auxiliou a aluna desenvolver outros entendimentos sobre a tragédia. Para tal, Fátima acrescentou um dado relevante em seu relato, destacando que seu entendimento inicial sobre o rompimento da barragem foi alterado, ou seja, de "acidente" para um "crime" precisamente. Ainda com vistas ao "novo" entendimento de Fátima sobre o evento, atribuímos essa nova concepção ao actante jornal, uma vez que ele se apresentou como um elo entre o aluno-leitor e o mundo externo, possibilitando aos alunos se interagirem com as nuances do desastre.

Tal entendimento também pôde ser atribuído as discussões e debates, realizadas entre os alunos e o professor, em que uma vasta rede de elementos, concepções e intencionalidades estavam associadas. Nesse caminho, o professor "construtor" direcionou a oficina para uma análise mais pormenorizada a respeito do desastre, em que inúmeros recursos foram possibilitados pelo professor aos alunos.

Notamos ainda a partir do registro de Fátima, a quantidade de detalhes referentes a tragédia. Ela procurou ser precisa em sua produção em relação: a data do desastre, as localidades atingidas, o número de vítimas, as empresas responsáveis, bem como as implicações pós-desastre. Aqui, ressaltamos a 
preocupação de Fátima, em relação aos "contornos" da tragédia, uma vez que em sua concepção o assunto já está sendo "esquecido" pela sociedade. Premissa esta que faz muito atual, uma vez parte da sociedade não têm ciência sobre os "rumos" que tomaram o desastre, no que tange a reparação do meio ambiente e o pagamento de indenizações aos atingidos.

Portanto, entendemos que tanto os jornais como alunos e professor, foram fundamentais para que a Fátima se tornasse uma aluna híbrida, heterogênea de natureza e cultura, numa mistura de elementos humanos e não-humanos. Tal perspectiva, vem de encontro com as nuances da TAR, em que os elementos humanos e não-humanos nunca são dissociados.

\section{CONSIDERAÇÕES FINAIS}

O presente trabalho apresentou e analisou as controvérsias mobilizadas a partir de uma oficina pedagógica com matérias de jornais que circularam na Região dos Inconfidentes sobre o rompimento da Barragem de Fundão. Até a presente data, o desastre da Samarco se apresenta com poucas soluções com inúmeros processos judiciais impetrados contra a empresa encontram-se paralisados, causando agora o que denominamos de "tragédia processual".

Tal cenário agrava-se uma vez que muitos atingidos não são assistidos da maneira como deveriam, além do rio Doce padecer em face de grande lama de rejeitos. Ademais, temos cidades com inúmeras dificuldades, com grande número de desempregados e uma economia arrefecida.

Nosso suporte para as análises dos episódios apresentados se basearam nos pressupostos teóricos da TAR. Acreditamos que dessa forma, fomentamos ainda mais esta área de estudos com publicações, que tomam os materiais, como os jornais, no mesmo plano de importância que os humanos, no caso alunos e professor.

Destacamos ainda, que por meio da oficina podemos avaliar o nosso produto educacional desenvolvido no mestrado, ou seja, o caderno de oficina para professores da educação básica. Entendemos que a partir das análises das controvérsias, o caderno pôde instigar nos alunos diferentes perspectivas 
em relação a esta tragédia, sendo um importante elemento para mais práticas sociomateriais nas escolas. Além disso, nos possibilitou compreender e aprofundar as análises das redes e as interações entre humanos e nãohumanos na formação de novos elementos híbridos de natureza e cultura.

Portanto, diante as concepções defendidas neste trabalho, a oficina com jornais pôde suscitar nos alunos premissas importantes para ser disseminadas na sociedade como os da reflexão, crítica, democracia e justiça social, perante a exploração mineral não só na região dos Inconfidentes, mas em todo o Brasil.

\section{REFERÊNCIAS}

ANASTASIOU, Léa Graças Camargos; ALVES, Leonir Pessate. Estratégias de ensinagem. Processos de ensinagem na universidade: pressupostos para as estratégias de trabalho em aula. v. 3, p. 67-100, 2004.

BRASIL. Lei № 12.334, de 20 de setembro de 2010. Disponível em: <http://www.planalto.gov.br/ccivil_03/_ato2007-2010/2010/lei/l12334.htm>. Acesso em: 14 nov. 2018.

CARMO, Roberto Luiz et al. Reflexões sobre um desastre. Revista Jurídica CONSULEX, Ano XX, n. 455, jan. 2016. p. 30-35.

CEAT - Central de Apoio Técnico. Inquérito Civil no 0105.15.002048-2: qualidade da água no município de Governador Valadares, após o desastre ambiental causado pelo rompimento das barragens da SAMARCO MINERAÇÃO S/A. 2016. 16p.

CERRETO, Clovis e DOMENICO, Silvia Marcia Russi. Mudança e Teoria AtorRede: Humanos e não humanos em controvérsias na implementação de um Centro de Serviços Compartilhados. Cad. EBAPE.BR, Rio de Janeiro, v. 14, n. 1, Artigo 5, 2016. 33p.

DNPM- Departamento Nacional de Produção Mineral. 2016. Classificação das Barragens de Mineração inseridas na PNSB - data base 12/2016. Disponível em: <http://www.dnpm.gov.br/assuntos/barragens/arquivosbarragens/ CADASTRO\%20NACIONAL\%20DE\%20BARRAGENS_ 2016\%20_FINAL\%2006-01-2017.pdf>. Acesso em: 19 out. 2018.

GIAIA - Grupo Independente para avaliação de impacto ambiental. Relatório-técnico determinação de metais na bacia do Rio Doce (período: dezembro-2015 a abril-2016). 2016. 71p. 
IBRAM- Instituto Brasileiro de Mineração. 2016. Gestão e Manejo de Rejeitos da Mineração. Disponível em: <http://www.ibram.org.br/sites/1300/1382/00006222.pdf>. Acesso em 18 out. 2018.

IGAM- Instituto Mineiro de Gestão das Águas. Monitoramento da qualidade das águas superficiais do Rio Doce no estado de Minas Gerais. Secretaria de Estado de Meio Ambiente e Desenvolvimento Sustentável - SEMAD. 2016. 97 p.

LATOUR, Bruno. The pasteurization of France. Cambridge, MA: Harvard University Press, 1993.

LATOUR, Bruno. Jamais fomos modernos. Rio de Janeiro: Ed. 34, 1994.

LATOUR, Bruno. Pandora's hope. Essays on the reality of science studies. Cambridge, Mass.: Harvard University Press. 1999.

LATOUR, Bruno. Ciência em ação: como seguir cientistas e engenheiros sociedade afora. São Paulo: Ed. Unesp, 2000.

LATOUR, Bruno. A esperança de Pandora: ensaios sobre a realidade dos estudos científicos. Bauru, SP: Edusc, 2001.

LATOUR, Bruno. Reagregando o social. Salvador: Ed UFBA, 2012. 400 p.

MOITA, Filomena M. G. S. Cordeiro e ANDRADE, Fernando Cézar. B. O saber de mão em mão: a oficina pedagógica como dispositivo para a formação docente e a construção do conhecimento na escola pública. Reunião anual da ANPED, v. 29, p.16, 2006.

OLIVEIRA, Kaio Eduardo Jesus; Educação e Teoria Ator-Rede: fluxos heterogêneos e conexões híbridas. Ilhéus: Editus, 2016. 139p.

PCMG- Polícia Civil de Minas Gerais. Disponível em:

<http://www.agenciaminas.mg.gov.br/news/pdf/97731.pdf>. Acesso em 18 out. 2018.

PORTO, Marcelo Firpo Souza. A tragédia da mineração e do desenvolvimento no Brasil: desafios para a saúde coletiva. Cad. Saúde Pública, Rio de Janeiro, 32(2): e00211015, fev. 2016. 3p.

SERRA, Cristina. Tragédia em Mariana: a história do maior desastre ambiental do Brasil. Rio de Janeiro: Record, 2018. 461p.

SILVA, Cíntia Charlene e BALTAZAR, Glória Maria Oliveira. A Grande Reportagem: os desafios enfrentados pelos profissionais desde a ideia da pauta até a divulgação da matéria. Juiz de Fora: UFJF, 2013. 132p. 
SILVA, Fabio Augusto Rodrigues et al. Teoria Ator-Rede, literatura e educação em ciências: uma proposta de materialização da rede sociotécnica em sala de aula. Revista Ensaio, Belo Horizonte, 2016. 18p.

SOARES, Jiane Martins. As contribuições do jornal no trabalho com a leitura. Disponível em :

http://acervo.plannetaeducacao.com.br/portal/imagens/artigos/gramatica/ARTIG O\%20JIANE\%20JORNAL\%20ITAPEMA.pdf. 14p. Acesso em: 07-07-2019.

VELHO, Lea; VELHO, Paulo. A controvérsia sobre o uso de alimentação 'alternativa' no combate à subnutrição no Brasil. História, Ciências, Saúde, v.9, n. 1, p. 125-157, 2002.

VENTURINI, Tommaso. Diving in magma: how to explore controversies with actor-network theory. Public Understanding of Science, v. 19, n. 3, p. 258273, 2010a.

Recebido em: 01/12/2018

Aprovado em: 19/09/2019 